\title{
Article \\ Storage Stability and In Vitro Bioaccessibility of Liposomal Betacyanins from Red Pitaya (Hylocereus polyrhizus)
}

\author{
Xian Lin ${ }^{1,2} \oplus$, Bozhe $\mathrm{Li}^{1}$, Jing Wen ${ }^{1}$, Jijun Wu ${ }^{1}$, Daobang Tang ${ }^{1}$, Yuanshan Yu ${ }^{1}$, Yujuan $\mathrm{Xu}{ }^{1, *}$ and Baojun $\mathrm{Xu}{ }^{2, *} \mathbb{C}$ \\ 1 Sericultural \& Agri-Food Research Institute, Guangdong Academy of Agricultural Sciences/Key Laboratory \\ of Functional Foods, Ministry of Agriculture and Rural Affairs/Guangdong Key Laboratory of Agricultural \\ Products Processing, Guangzhou 510610, China; sannylam@126.com (X.L.); libozhe19@163.com (B.L.); \\ wenjing@gdaas.cn (J.W.); guoshuwujijun@163.com (J.W.); tangdaobang@gdaas.cn (D.T.); \\ yuyuanshan@gdaas.cn (Y.Y.) \\ 2 Food Science and Technology Program, BNU-HKBU United International College, Zhuhai 519087, China \\ * Correspondence: guoshuxuyujuan@163.com (Y.X.); baojunxu@uic.edu.cn (B.X.); Tel.: +86-20-87237279 (Y.X.); \\ $+86-756-3620636$ (B.X.)
}

check for updates

Citation: Lin, X.; Li, B.; Wen, J.; Wu, J.; Tang, D.; Yu, Y.; Xu, Y.; Xu, B. Storage Stability and In Vitro Bioaccessibility of Liposomal Betacyanins from Red Pitaya (Hylocereus polyrhizus). Molecules 2022, 27,1193. https://doi.org/10.3390/ molecules27041193

Academic Editors: Rita Cortesi and Kumar Ganesan

Received: 31 December 2021

Accepted: 7 February 2022

Published: 10 February 2022

Publisher's Note: MDPI stays neutral with regard to jurisdictional claims in published maps and institutional affiliations.

Copyright: (C) 2022 by the authors. Licensee MDPI, Basel, Switzerland. This article is an open access article distributed under the terms and conditions of the Creative Commons Attribution (CC BY) license (https:// creativecommons.org/licenses/by/ $4.0 /)$.
Abstract: In order to address the poor stability of the betacyanins from red pitaya (Hylocereus polyrhizus, HP), which are considered as good sources of natural colorant, liposomal-encapsulation technique was applied in this study. Thin-layer dispersion method was employed to prepare HP betacyacnin liposomes (HPBL). The formulation parameters for HPBL were optimized, and the characteristics, stability, and release profile of HPBL in in vitro gastrointestinal systems were evaluated.Results showed that an HP betacyanin encapsulation efficiency of $93.43 \pm 0.11 \%$ was obtained after formulation optimization. The HPBL exhibited a narrow size distribution of particle within a nanometer range and a strong electronegative $\zeta$-potential. By liposomal encapsulation, storage stability of HP betacyanin was significantly enhanced in different storage temperatures. When the environmental $\mathrm{pH}$ ranged from 4.3-7.0, around $80 \%$ of HP betacyanins were preserved on Day 21 with the liposomal protection. The loss of 2,2'-Diphenyl-picrylhydrazyl (DPPH) scavenging activity and color deterioration of HPBL were developed in accordance with the degradation of HP betacyanins during storage. In in vitro gastrointestinal digestion study, with the protection of liposome, the retention rates of HP betacyanins in vitro were enhanced by $14 \%$ and $40 \%$ for gastric and intestinal digestion, respectively.This study suggested that liposomal encapsulation was an effective approach to stabilize HP betacyanins during storage and gastrointestinal digestion, but further investigations were needed to better optimize the liposomal formulation and understand the complex liposomal system.

Keywords: red pitaya; betacyanin; liposome; storage stability; bioaccessibility

\section{Introduction}

Hylocereus pecies, commonly known as pitaya or dragon fruit, belong to the order Caryophyllales. They originate from the American continent and are now cultivated on a large scale in South China, Malaysia, Vietnam, Thailand, and some other parts of the world. The fruit has rich sources of nutrients and abundant bioactive compounds including flavonoids, crude fiber, betalains, carotenes, and polyphenols [1]. Hylocereus polyrhizus $(\mathrm{HP})$ is a kind of Hylocereus species with attractive red color in peel and flesh. The red color is endowed by water-soluble vacuolar pigments—-betacyanins, which are immonium conjugates of betalamic acid with cyclo-DOPA [2]. Due to this, HP has been identified as a potential source of betacyanins that can be used as natural pigments in the food industry. Besides the appealing color, betacyanins are also considered as significant phytochemicals with potential health benefit effects for human beings. Numerous in vitro and ex vivo studies have confirmed that betacyanins possess antioxidant activity and have anti-tumor 
effects in animal models and in cancerous cell lines [3]. Therefore, the application of HP as a source of betacyanins pigments could have great potential on the natural colorant market.

However, the unstable physicochemical stability of betacyanins may cause significant loss of chromatic characteristics and bioactive potential during processing, storage, and digestion, limiting their applications as natural functional colorants. Previous studies have demonstrated that betacyanins were susceptible to environment factors. Exposure to light, oxygen, high water activity, metal ions, and high temperature could all lead to the degradation of betacyanins [4]. The instability of physicochemical property could also affect the bioavailability of betacyanins, which plays a vital role in the functioning of their biological properties. Krantz et al. compared the differences in excretion of betanin when the rats were given betanin from beetroot extract by intravenous injection or oral administration [5]. Results showed that when given by intravenous injection, betanin was almost completely recovered in the urine, but only 3\% was recovered in the urine and 3\% in the feces after $24 \mathrm{~h}$ when given orally. To date, a number of in vitro studies have evidenced the significant loss of betacyanins in stimulated GI digestion, limiting the bioaccessibility of betacyanins [3].

Liposome is self-assembled closed vesicle with a phospholipid bilayer structure, the particle size of which varies from $10 \mathrm{~nm}$ to several micrometers. Liposomes contain polar, non-polar, and amphiphilic regions within phospholipid bilayer compartment, which enable the encapsulation of both lipophilic and hydrophilic compounds [6]. The application of the liposomal system as a nano-carrier for the delivery of bioactive compounds has been considered as a potential tool to overcome series limitations associated with environmentalinstability, poor solubility, gastrointestinal degradation, low bioavailability, uncontrolledrelease, and unspecific delivery [7]. The stability of a liposome is crucial for the delivery of the entrapped compound. Preparation technique, operating parameters, and formulation parameters could all play a significant role in the liposomal preparation. To date, several bioactive compounds such as quercetin, vitamin C, curcumin, resveratrol, and capsaicin, have been successfully entrapped in liposomes with improved solubility, bioavailability, and biological activity [6].

Thus, in this study, in order to address the poor stability and bioavailability of HP betacyanins, liposomal-encapsulation technique was applied. Formulation parameters of HPBL by the thin-layer dispersion method were optimized based on the encapsulation efficiency. Moreover, characteristic, stability, and release profile of HPBL in invitro gastrointestinal systems were evaluated. The results could provide important information for the design of HPBL, aiming their application at the functional food industry.

\section{Results and Discussions}

\subsection{Optimization of the Formulation Parameters for Preparation of HPBL}

Model fitting. The values of responses of encapsulation efficiency (EE) of HP betacyanins at different experimental combinations are given in Table 1, which show considerable variations in the encapsulation efficiency of HP betacyanins under different thin-layer dispersion conditions. The multiple regression analysis was applied to the experiment data, and the response variable and the test variables can be expressed by the following second-order polynomial equation:

$\mathrm{Y}=88.85-4.40 \mathrm{X}_{1}-1.10 \mathrm{X}_{2}-1.51 \mathrm{X}_{3}+0.64 \mathrm{X}_{1} \mathrm{X}_{2}-0.386 \mathrm{X}_{1} \mathrm{X}_{3}-1.98 \mathrm{X}_{2} \mathrm{X}_{3}-6.59 \mathrm{X}_{1}^{2}+1.03 \mathrm{X}_{2}^{2}+1.04 \mathrm{X}_{3}^{2}$

where $\mathrm{Y}$ is the EE of HP betacyanins, and $\mathrm{X}_{1}, \mathrm{X}_{2}$, and $\mathrm{X}_{3}$ are the coded variables for HP extract concentration, lecithin-to-cholesterol ratio, and lecithin concentration, respectively.

The analysis of variance (ANOVA) is listed in Table 2 for the fitted quadratic polynomial model of EE of HP betacyanins. Results suggested that the model was significant $(p<0.05)$ with a non-significant lack of fit $(p>0.05)$, indicating it was adequate for predicting the EE of HP betacyanins under any combination of values of the variables. The variance of the quadratic regression model showed that the determination coefficient $\left(R^{2}\right)$ 
was 0.9536 , implying that only $4.64 \%$ of the total variations were not explained by the model. An adjusted $R^{2}$ of 0.8939 further confirmed the model was highly significant.

Table 1. Central Composite Design Matrix and The Response Values for The EE of Betacyanin in HPBL.

\begin{tabular}{|c|c|c|c|c|c|c|c|}
\hline \multirow{2}{*}{ No. } & \multicolumn{2}{|c|}{$\begin{array}{c}\text { A: HP Extract } \\
\text { Concentration }(\mathrm{g} / \mathrm{mL})\end{array}$} & \multicolumn{2}{|c|}{ B: Lecithin-to-Cholesterol Ratio } & \multicolumn{2}{|c|}{ C: Lecithin Concentration $(\mathrm{g} / \mathrm{mL})$} & \multirow{2}{*}{$\begin{array}{l}\text { EE } \\
(\%)\end{array}$} \\
\hline & $\mathbf{X 1}$ & Code X1* & $\mathrm{X} 2$ & Code $X 2 *$ & $\mathrm{X} 3$ & Code X3 * & \\
\hline 1 & 0.125 & 0 & 0.000 & $-\alpha$ & 0.018 & 0 & $90.34 \%$ \\
\hline 2 & 0.125 & 0 & 5.000 & 0 & 0.018 & 0 & $88.19 \%$ \\
\hline 3 & 0.125 & 0 & 5.000 & 0 & 0.006 & $-\alpha$ & $93.28 \%$ \\
\hline 4 & 0.200 & $\alpha$ & 5.000 & 0 & 0.018 & 0 & $61.72 \%$ \\
\hline 5 & 0.080 & -1 & 7.973 & 1 & 0.025 & 1 & $85.80 \%$ \\
\hline 6 & 0.170 & 1 & 2.027 & -1 & 0.011 & -1 & $80.41 \%$ \\
\hline 7 & 0.125 & 0 & 5.000 & 0 & 0.018 & 0 & $89.19 \%$ \\
\hline 8 & 0.080 & -1 & 2.027 & -1 & 0.011 & -1 & $93.75 \%$ \\
\hline 9 & 0.170 & 1 & 7.973 & 1 & 0.025 & 1 & $74.48 \%$ \\
\hline 10 & 0.050 & $-\alpha$ & 5.000 & 0 & 0.018 & 0 & $75.84 \%$ \\
\hline 11 & 0.170 & 1 & 7.973 & 1 & 0.011 & -1 & $84.65 \%$ \\
\hline 12 & 0.125 & 0 & 10.000 & $\alpha$ & 0.018 & 0 & $90.24 \%$ \\
\hline 13 & 0.125 & 0 & 5.000 & 0 & 0.030 & $\alpha$ & $87.42 \%$ \\
\hline 14 & 0.125 & 30 & 5.000 & 0 & 0.018 & 0 & $89.66 \%$ \\
\hline 15 & 0.081 & -1 & 2.027 & -1 & 0.025 & 1 & $92.05 \%$ \\
\hline 16 & 0.080 & -1 & 7.973 & 1 & 0.011 & -1 & $88.93 \%$ \\
\hline 17 & 0.170 & 1 & 2.027 & -1 & 0.025 & 1 & $83.67 \%$ \\
\hline
\end{tabular}

* The code numbers of $0,-1,1,-\alpha$, and $\alpha$ represented the center point, factorial point, factorial point, axial point, and axial point in the central composite design, respectively.

Table 2. Analysis of Variance of Regression Model.

\begin{tabular}{cccccc}
\hline Variables & $\begin{array}{c}\text { Sum of } \\
\text { Squares }\end{array}$ & df & $\begin{array}{c}\text { Mean } \\
\text { Square }\end{array}$ & F-Value & $\begin{array}{c}p \text {-Value } \\
\text { Prob. }>\text { F }\end{array}$ \\
\hline Model & 1015.64 & 9 & 112.85 & 15.98 & 0.0007 \\
A-HP extract concentration & 264.15 & 1 & 264.15 & 37.41 & 0.0005 \\
B-Lecithin-to-cholesterol ratio & 16.67 & 1 & 16.67 & 2.36 & 0.1683 \\
C-Lecithin concentration & 31.06 & 1 & 31.06 & 4.4 & 0.0742 \\
AB & 3.28 & 1 & 3.28 & 0.464 & 0.5176 \\
AC & 1.19 & 1 & 1.19 & 0.1688 & 0.6935 \\
BC & 31.42 & 1 & 31.42 & 4.45 & 0.0729 \\
A $^{2}$ & 489.34 & 1 & 489.34 & 69.3 & $<0.0001$ \\
B $^{2}$ & 11.91 & 1 & 11.91 & 1.69 & 0.2353 \\
C $^{2}$ & 12.15 & 1 & 12.15 & 1.72 & 0.231 \\
Lack of fit & 48.3 & 5 & 9.66 & 17.11 & 0.0561 \\
Residual & 49.43 & 7 & 7.06 & & \\
Pure error & 1.13 & 2 & 0.5646 & & \\
Correlation total & 1065.07 & 16 & & & \\
\hline
\end{tabular}

As shown in Table 2, independent variable $\mathrm{A}$ and quadratic term $\mathrm{A}^{2}$ significantly affected the EE of HP betacyanins. From Figure $1 a, b$, it was seen that the effects of HP extract concentration on the EE of HP betacyanins presented a peak in the EE of HP betacyanins when the HP extract concentration ranged from 0.050 to $0.200 \mathrm{~g} / \mathrm{mL}$. The results suggested that at lower and higher level of extract concentration, EE was positively and negatively related with the extract concentration, respectively. Similarly, Guldiken et al. found that when the concentration of anthocyanin-rich black carrot extract increased from $10 \%$ to $40 \%$, the EE of phenolics decreased accordingly [8]. Zhao et al. found an increase of anthocyanin concentration from $0.1 \%$ to $0.5 \%$ led to a significant increase $(p<0.05)$ in the EE of anthocyanins [9]. 

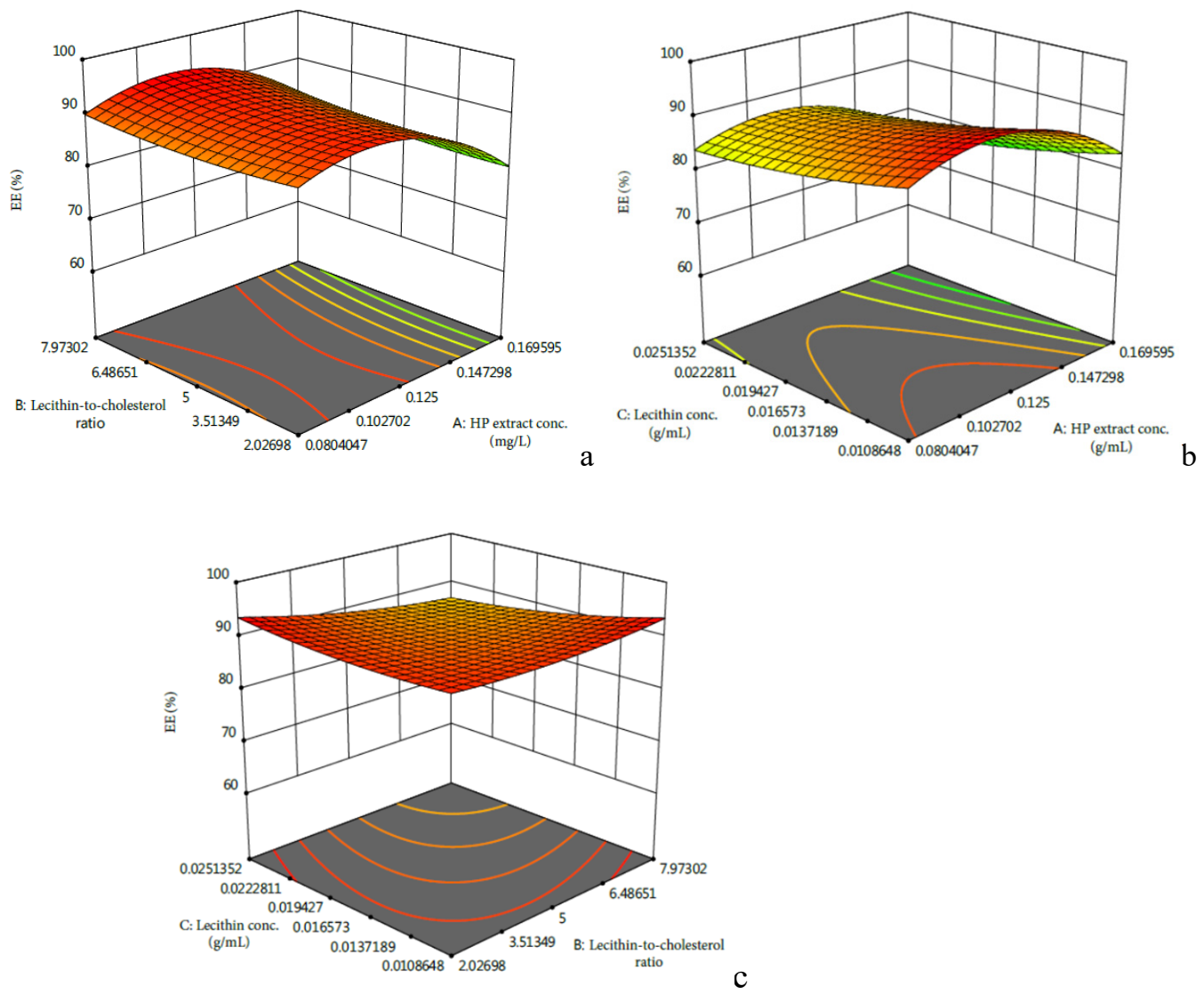

Figure 1. Response surface plots showing the effects of HP extract concentration, lecithin-tocholesterol ratio, and lecithin concentration on the EE of HPBL: (a) interactive relationships between HP extract concentration and lecithin-to-cholesterol ratio; (b) interactive relationships between HPextract concentration and lecithin concentration; (c) interactive relationships betweenlecithin-tocholesterol ratio and lecithin concentration.

Figure 1c indicated that the EE of HPBL increased with the decrease of B or C. However, as Table 2 suggested, the effects of factor $B$ and $C$, as well as their interactive relationships, were not significant $(p>0.05)$. Thus, in order to maximize the lecithin-to-cholesterol ration and minimize the lecithin concentration, the optimized parameters were determined to be an $\mathrm{HP}$ extract concentration of $0.104 \mathrm{~g} / \mathrm{mL}$, a lecithin-to-cholesterol ratio of 7.9:1, and a lecithin concentration of $0.011 \mathrm{~g} / \mathrm{mL}$, which was predicted to have an EE of $93.30 \%$.

Validation ofthe model. To validate the accuracy of the model equation, a further experiment was carried out with the optimal condition. Results showed the practical EE was $93.43 \pm 0.11 \%$, which matched well with the predicted value. Thus, it was confirmed that the regression model was accurate and adequate for the prediction of encapsulation efficiency of HP betacyanins.

\subsection{Characterization of the HPBL}

The performance of liposomes is strongly related to their characteristics. Liposomes can be characterized in terms of $\zeta$-potential, particle size, and polydispersity index [8]. Results of characterization of HPBL are shown in Figure 2. As seen in Figure 2a, results of Sephadex ${ }^{\circledR}$ G50 filtration displayed the separation of HPBL and unencapsulated HP betacyanins (FHPB), as the peak of HPBL occurred only in the HPBL dispersion group at a wavelength of $538 \mathrm{~nm}$, which was the wavelength of the absorption maximum of betacyanins. 

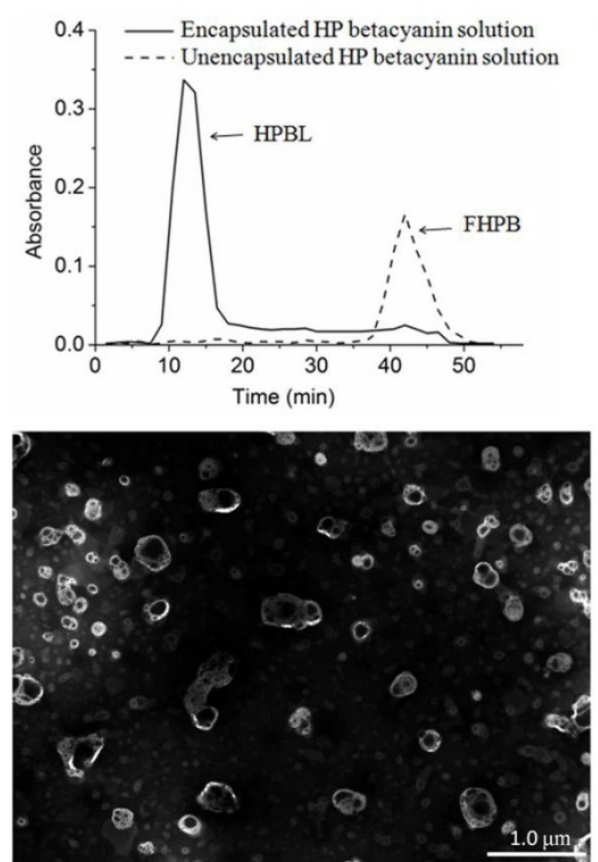

a

\begin{tabular}{ccc}
\hline $\begin{array}{c}\text { Z-average } \\
(\mathrm{nm})\end{array}$ & $\begin{array}{c}\zeta \text {-potential } \\
(\mathrm{mV})\end{array}$ & $\begin{array}{c}\text { Polydispersity } \\
\text { index }\end{array}$ \\
\hline $134.35 \pm 7.95$ & $-59.14 \pm 4.93$ & $0.26 \pm 0.07$
\end{tabular}

C

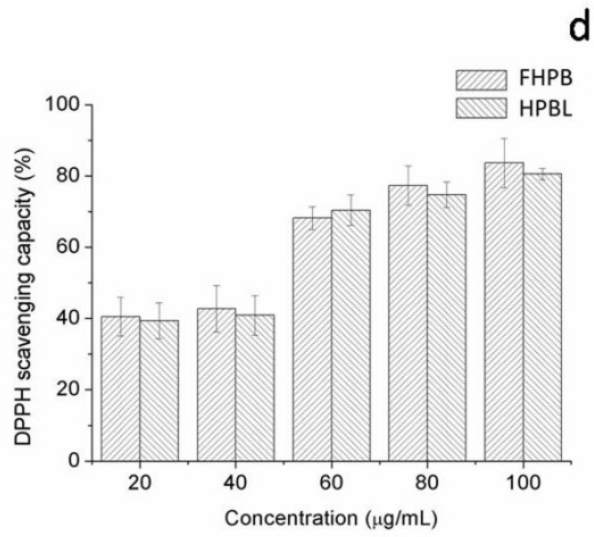

Figure 2. Physicochemical characteristics of HPBL: (a) Absorbance of encapsulated HP betacyanin solution and unencapsulated HP betacyanin (FHPB) solution with a wavelength of $538 \mathrm{~nm}$ as sepa-

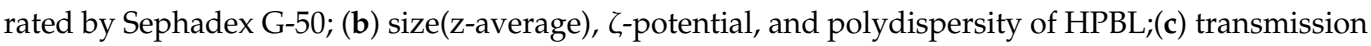
electron microscopy observation of HPBL; (d) DPPH free radical scavenging rate.

Particle size is an important factor of liposomes for the oral delivery of bioactive compounds, as particle size determined the absorption efficiency in the gastrointestinal tract, biodistribution, and pharmacokinetic profiles [9]. Andar et al. investigated the cellular uptake of liposomes with mean diameters ranging from $40.6 \mathrm{~nm}$ to $276.6 \mathrm{~nm}$ in Caco-2 cells and found the uptake of liposome was markedly negatively correlated with its size [10]. It was also reported that as the size of liposome decreased from 400 to $40 \mathrm{~nm}$, a longer blood circulation was observed. In addition, the prolonged blood circulation tended to enhance the accumulation of entrapped ingredients in targeted sites. Based on the collected data, Nagayasu et al. concluded that the maximum tumor accumulation of liposomes was around $100 \mathrm{~nm}$ in diameter [11]. In the current study, as Figure 2b shows, the z-average of HPBL was $134.35 \pm 7.95 \mathrm{~nm}$, which is in optimal size range and could enhance the bioavailability by oral delivery.

The $\zeta$-potential is regarded as an indicator of particle stability in the colloidal system. With a high $\zeta$-potential, normally above $30 \mathrm{mV}$ or below $-30 \mathrm{mV}$, particles will repel each other and decrease the tendency of aggregation and enhance the dispersibility in the aqueous media [12]. As seen in Figure 2b, the $\zeta$-potential of HPBL presented a strong electronegative value, which was below $-30 \mathrm{mV}$, suggesting the HPBL was physically stable. Compared to the $\zeta$-potential of betanin-loaded liposomes of $-19.05 \pm 1.65 \mathrm{mV}$, the HPBL's $\zeta$-potential was greatly increased, which could be attributed to the more negative charges offered by the HP betacyanins [13].

Another source of information on the quality of a liposome formulation is the PDI. The higher PDI values of the liposomes indicated a broader size distribution or the development of a bimodal particle size distribution. PDI $<0.3$ is considered as an ideal and narrow size distribution of particle [6]. Figure $2 b$ displays that the PDI of HPBL was in the range of 0.2 to 0.3 , indicating a low polydispersity. This value was in accordance with the results of Da Silva Malheiros et al. and Marín et al., as liposomes prepared from biological materials were expected in this range $[12,14]$. 
The morphology of HPBL was observed by transmission electron microscopy (TEM) as shown in Figure 2c. It was confirmed that the sizes of HPBLs were mainly around $134.35 \mathrm{~nm}$, which matched the results of the particle size. Moreover, the morphology of HPBL appeared to be heterogeneous vesicles, which was similar with those liposomes prepared in the studies of Amjadi et al. and Zhao \& Temelli, as the thin film hydration method led to the production of liposomes with unilamellar and multilamellar structures $[13,15]$. The complex composition of extracted HP betacyanins solution and the capacity of liposomes to encapsulate compounds with different polarities could also be explained for the irregular shape of HPBL instead of the spherical shape. Owning bothwater and lipid phase, liposomes could encapsulate hydrophobic, hydrophilic, or amphiphilic compounds. For hydrophilic compounds like betacyanins, they could be entrapped in the inner aqueous phase or adhered on the surfaces of the liposomes. For hydrophobic compounds like some flavonoids, they could be embedded between the lipid bilayers of liposomes [6].

Betacyanins, which are similar with phenolic compounds in terms of structure and function, were demonstrated to be excellent antioxidant phytochemicals [16]. Evidences showed that betacyanins could protect against oxidative stress-related diseases, owing to it strong antioxidant capacity. The antioxidant capacity of betacyanins was reported to be due to their high radical scavenging activity. The radical scavenging activity of betacyanin functions by being oxidized by free radicals. Once oxidized, the structure of betacyanins will be broken down into thecore structure betalamic acid and other small molecules [17]. There are various methods to evaluate the radical scavenging activity. Among them, the DPPH assay is a frequently used method as it can rapidly determine the radical scavenging activity.The DPPH scavenging activity of the betacyanins could be determined by the numbers of hydroxyl/imino groups, the positions of hydroxyl groups, and glycosylation of aglycones in the betacyanin molecules [18].Thus, different betacyanins have different levels of free radical scavenging activity due to the distinction of the structure. For example, betanidin with a catechol group possessed greater free radical scavenging activity than those of the glycoside of betacyanins [18]. Figure 2d displays the DPPH scavenging activity of FHPB and HPBL between betacyanin concentrations of 20 and $100 \mu \mathrm{g} / \mathrm{mL}$. Results showed that no significant difference was observed between FHPB and HPBL, suggesting that liposomal encapsulation had no impact on the antioxidant capacity of HP betacyanins. Similarly, Malheiros found liposomal encapsulation did not affect the biological activity of the loaded bioactive compounds [14].

\subsection{Storage Stability of HPBL}

\subsubsection{Temperature}

The stability of HPBL in storage temperature conditions of $4{ }^{\circ} \mathrm{C}, 25^{\circ} \mathrm{C}$, and $37^{\circ} \mathrm{C}$ is shown in Figure 3. As Figure 3a displays, the betacyanin retention rate decreased with the increase of storage temperature. Especially, when the storage temperature raised from $25^{\circ} \mathrm{C}$ to $37^{\circ} \mathrm{C}$, the retention rate of FHPB dropped by $89 \%$ on Day 21. By comparison with FHPB, betacyanin retention in HPBL was enhanced in all storage temperature conditions during a storage period of 21 days, indicating the protective effects of liposomal encapsulation. The retention rates of $\mathrm{HPBL}$ storing at $4{ }^{\circ} \mathrm{C}, 25^{\circ} \mathrm{C}$ and $37^{\circ} \mathrm{C}$ reached $75.54 \%, 67.57 \%$, and $20.28 \%$ on Day 21, which were improved by $44 \%, 33 \%$ and $271 \%$, respectively. However, when stored at a high temperature of $37{ }^{\circ} \mathrm{C}$, even with liposomal encapsulation, the betacyanin retention rate was only $11.06 \%$ by the end of the storage, showing the severe heat-sensitivity of HPBL. Consistent with our current results, Amjadi et al. successfully improved the stability of betanin in gummy candies by liposomal encapsulation of betanins and prevented the betanin from the hydrolysis and oxidation conditions [18]. Liu et al. found that, in the temperature variation range of $20-90{ }^{\circ} \mathrm{C}$, the stability of curcumin was significantly improved during storage with the protection of liposome [19]. However, the retention rate of liposomal betacyanins still decreased significantly. 

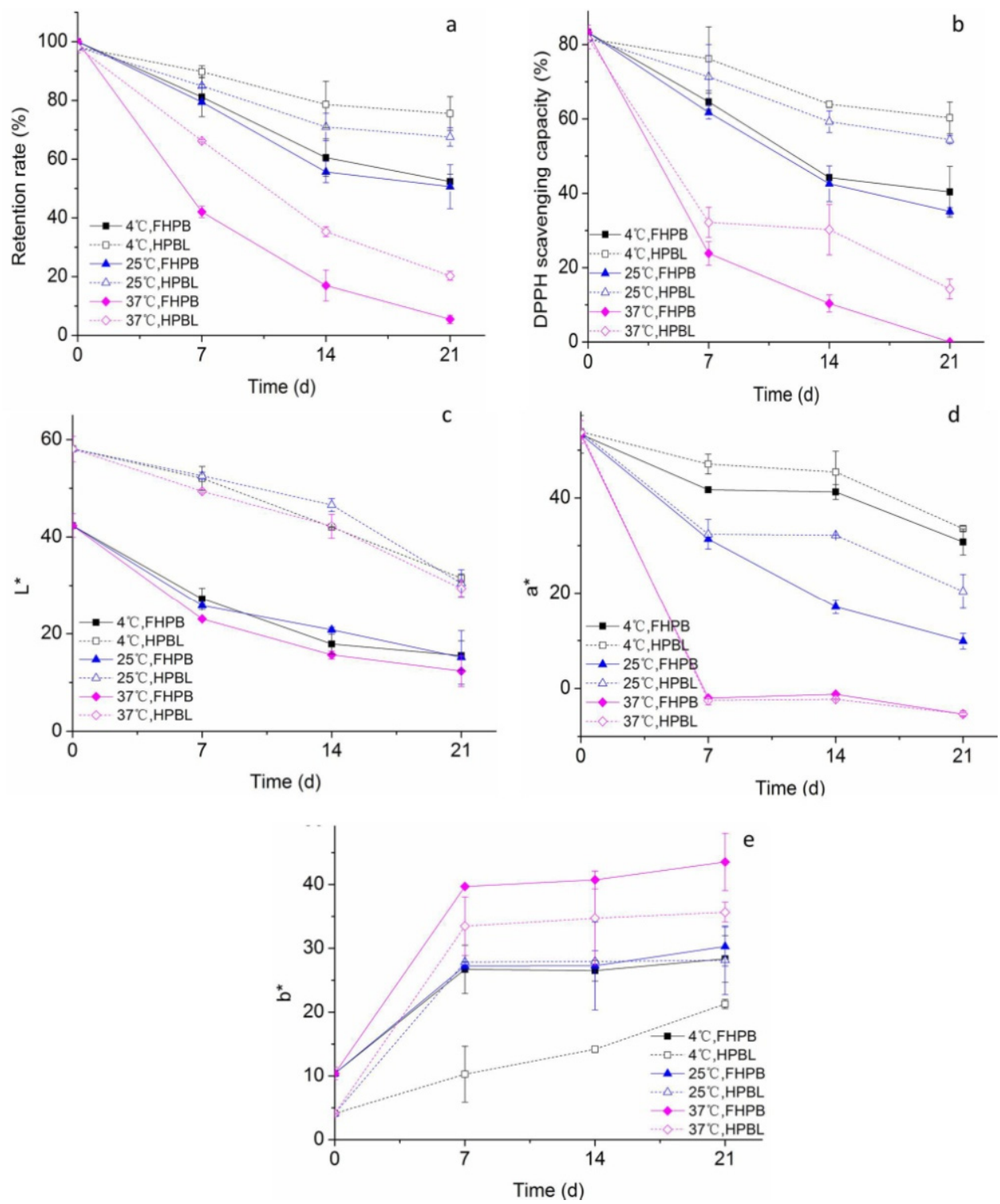

Figure 3. Stability of HPBL under different storage temperatures: (a) Retention rate; (b) DPPH scavenging activity; (c) $L^{*}$ value, which represents the color of lightness; (d) $a^{*}$ value, which represents the color redness when the value is positive; and (e) $b^{*}$ value, which represents the color of yellowness when the value is positive.

Temperature is a crucial influencing factor for both betacyanin and liposome stability. Generally, the liposomal particles have a high tendency to degrade, flocculate, fusion, or aggregate, leading to the leakage of entrapped bioactive compounds during storage or after administration [19]. Release of the encapsulated compound in liposome depends greatly on the characteristic of the compound. For hydrophobic compounds, their diffusion from the bilayer core to the aqueous solution could be inhibited due to the interactions, such as van der Waals' interactions, hydrophobic interactions, and hydrogen bonds. However, the release of a hydrophilic compound could probably happen by permeating across the liposomal membrane, to some extent which depends on the structure of the liposome and the properties of the encapsulated compound [20]. Maherani et al. revealed that the hydrophilic compound calcein could permeate across the liposomal membrane without membrane disruption [21]. As hydrophilic compounds, betacyanins might be encapsulated in the water phase of the liposome, embedded in the core of the liposome, or just adhering to the surface of liposome by electrostatic repulsive force [18]. Thus, betacyanins entrapped 
in the core of liposomes could be released by penetrating and crossing the liposomal membranes, and those adhering on the surfaces of liposomes might be isolated and released, leading to the gradual exposure of betacyanins to the environment during storage. With the increase of environmental temperature, the hydrophobic interactions and van der Waals forces in the liposomal bilayers became weaker and the permeability of bilayers increased, thus facilitating the leakage of the encapsulated compounds [6]. In addition, betacyanins are heat-sensitive [22]. Therefore, the increase of environmental temperature accelerated the degradation of liposomal betacyanins.

As Figure $3 \mathrm{~b}$ displays, the variations of DPPH scavenging capacity decreased in a similar manner with the betacyanin retention rate, suggesting that betacyanin concentration could be the major factor responsible for the antioxidant capacity of HPBL dispersion. By liposomal encapsulation, the DPPH scavenging capacity of HP betacyanin was effectively maintained during the storage. Similar to this study, Gandía-Herrero et al.found that, with encapsulation by matrixes of chitosan and maltodextrin, the stability and antioxidant capacities of betacyanins were effectively retained [23].

Color is the most important feature for betacyanins, when it is developed to be a natural colorant. Figure $3 \mathrm{c}-\mathrm{e}$ presents the color variation of the samples. As shown in Figure 3c, HPBL samples showed an obvious higher whiteness than FHPB samples. Similarly, Amjadi et al. also observed that the $L^{*}$ value was elevated in liposomal betanin, as the whiter appearance was conferred by lecithin [18]. With the increase of storage time, the whiteness of both HPBL and FHPB decreased gradually in all groups. As Figure $3 \mathrm{~d}$ showed, the variations of $a^{*}$ value also had high consistency with the betacyanin retention rate. Figure $3 \mathrm{e}$ shows that $b^{*}$ values of all samples increased during the storage period, suggesting the increase of the yellowness of the samples. This may be attributed to the degradation of betacyanins. The yellowness also increased with the increase of temperature. Storing at $37^{\circ} \mathrm{C}$, the yellowness of FHPB was increased by $54 \%$ as compared to those at $4{ }^{\circ} \mathrm{C}$ on Day21. With the protection of liposome, the shift to yellowness was significantly restrained. Consistently, treating the betacyanin-rich red beet juice with $85^{\circ} \mathrm{C}$ for $8 \mathrm{~h}$, a shift of the red-purple hues of red beet juice to yellow-orange ones was also found [18].

\subsection{2. $\mathrm{PH}$}

Previous studies reported that betacyanins were stable at a $\mathrm{pH}$ range of $\mathrm{pH} 3$ to 7 [24]. When the $\mathrm{pH}$ was over 7, the color of betacyanins was altered to be yellowish-brown [25]. Thus, changes of stability of HPBL were evaluated in $\mathrm{pH}$ between $\mathrm{pH} 3-7$. As Figure $4 \mathrm{a}$ shows, the variations of HPBL in $\mathrm{pH}$ conditions from 4.3-7.0 had similar patterns, which declined gently during storage and around $80 \%$ of betacyanins were preserved on Day 21 . It is noted that the highest betacyanin retention rate during the storage was observed at $\mathrm{pH}$ 7.0. However, in conditions of $\mathrm{pH} 3.0$, betacyanin retention rate of HPBL dropped markedly during storage, with over half of betacyanins degraded within 7 days.

Similar to the factor of temperature, the stability of the liposomes and encapsulated betacyaninsin different $\mathrm{pH}$ conditions could both affect the retention rate of liposomal betacyanins. Low $\mathrm{pH}$ condition could alter the surface charges of the liposome and lead to the aggregation of the liposomes when the electrostatic repulsive force is not big enough to sustain the stabilization of the dispersion [6]. However, the major reasons for the substantial reduction of liposomal acidic condition could be due to the degradation of the betacyanins released from the liposome. Similar to our results, Gandía-Herrero et al. found that the stability of betaxanthin was more stable at $\mathrm{pH} 6$ and 7 than at the $\mathrm{pH}$ values of 4, 5, and 8 [26]. Montes-Lora et al. found that betacyanins in the Ullucus tuberosus and Opuntia dillenii were more suitable in low-acidic foods ( $\mathrm{pH} 5$ and 6) than in $\mathrm{pH} 4$ condition [27]. The reasons for different stable ranges of $\mathrm{pH}$ may be attributed to the different environmental conditions as well as the different chemical structures of different betacyanins [28]. 

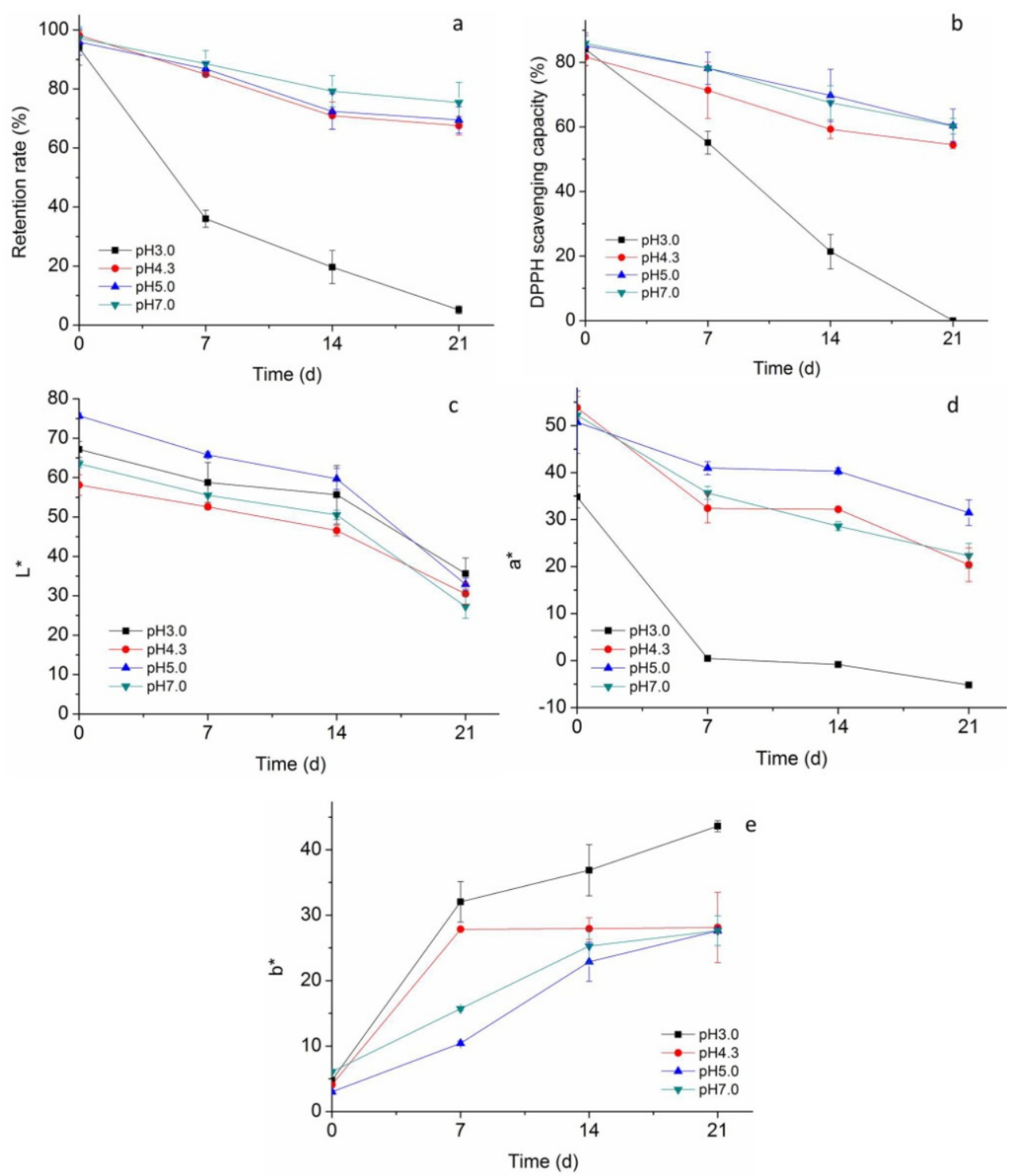

Figure 4. Stability of HPBL at different $\mathrm{pH}$ : (a) Retention rate; (b) DPPH scavenging activity; (c) $L^{*}$ value, which represents the color of lightness; (d) $a^{*}$ value, which represents the color rednesswhen the value is positive; (e) $b^{*}$ value, which represents the color of yellowness when the value is positive.

As Figure $4 \mathrm{~b}$ shows, the variation of DPPH scavenging activity was in high consistency with the retention rate. In $\mathrm{pH}$ conditions of 4.3-7.0, the DPPH scavenging activity was well maintained. Notably, the DPPH scavenging activity of HPBL was reduced by only $29 \%$ and $30 \%$ on Day 21 in $\mathrm{pH} 5.0$ and 7.0 conditions, respectively. However, the DPPH scavenging activity of HPBL in $\mathrm{pH} 3.0$ plummeted from $88.07 \%$ to 0 during the 21 days storage. In accordance with our results, Gliszczynska-Swiglo et al. found that the free radical scavenging activity of betanin was $\mathrm{pH}$-dependent, which was more active than some anthocyanins when the $\mathrm{pH}$ value was over 4 [29]. The $\mathrm{pH}$-dependent increase of free radical scavenging activity of betacyanins could be attributed to the formation of its different deprotonated forms. With the increase of $\mathrm{pH}$, betacyanins became better electron donators, thus leading to the increase in its free radical scavenging activity.Gandía-Herrero et al. investigated the free radical scavenging capacities of the structural unit of betaliansbetalamic acid and also found the $\mathrm{pH}$-dependence [30]. In addition, it was reported that betalamic acid displayed a notable increase in the radical scavenging capacity when the $\mathrm{pH}$ value was above $\mathrm{pH}$ 5.5. As for the color, Figure $4 \mathrm{c}$ shows the $L^{*}$ value of HPBL 
was susceptible to the $\mathrm{pH}$ conditions. The $L^{*}$ value changed the moment the $\mathrm{pH}$ was adjusted to a different value, and HPBL at $\mathrm{pH} 5.0$ and $\mathrm{pH} 4.3$ displayed the highest and the lowest whiteness, respectively. The whiteness of all groups decreased during the storage, especially with a higher rate from Day 14 to Day 21. Figure $4 \mathrm{~d}$ showed that the variation of $\mathrm{a}^{*}$ value (redness) was most like that of the betacyanins retention rate. Notably, $a^{*}$ value of HPBL in pH 3.0 decreased steeply and even reached minus value on Day 21, indicating the diminishing of redness and appearance of greenness. For the $b^{*}$ value, as Figure $4 \mathrm{e}$ displays, little difference was observed on Day 0 . However, after 7 days of storage, the $b^{*}$ values of HPBL in $\mathrm{pH} 3.0$ and 4.3 conditions were significantly higher than those in $\mathrm{pH}$ 5.0 and 7.0, indicating a more acidic environment led to the increase of yellowness. With a further increase of storage time, differences in the $b^{*}$ value of HPBL in $\mathrm{pH} 4.3,5.0$, and 7.0 conditions gradually uniformized, but that of the HPBL in pH 3.0 continuously went up and reached 43.62 on Day 21. The reason for severe discoloration of HPBL in pH 3.0 environment may be related to the unstable property of HP betacyanins and the instability of liposomes in this condition. As betacyanins are susceptible to hydrolysis at acidic $\mathrm{pH}$, similarly, Rodríguez-Sánchez et al. found that betaxanthins in Stenocereus pruinosus were most stable at $\mathrm{pH}$ 6.6 [31]. With the decrease of environmental $\mathrm{pH}$ value, the betaxanthin retention decreased accordingly. For liposomes, Liu found that in a low $\mathrm{pH}$ environment, the liposomes aggregated as the electrostatic repulsive force reduced [32]. Overall, the color of HPBL was highly related with the betacyanin retention rate andwas more stable in a low acidity environment. The degradation of betacyanins led to a gradual reduction of redness and the appearance of a brown shade.

\subsection{In Vitro Gastrointestinal Stability of HPBL}

The stability of the HPBL during the digestion process was evaluated under simulating digestion conditions of the stomach and the intestine. Betacyanin retention rate of HPBL during in vitro gastric and intestinal digestion is shown in Figure 5a. As it is shown, betacyanin retention rates of both FHPB and HPBL decreased gradually with the increase of time in the stimulated gastric digestion process. After $120 \mathrm{~min}$ of gastric digestion, the betacyanin retention rate of HPBL reached $70.96 \%$ and increased by $14 \%$ as compared to that of the FHPB. Betacyanin retention rate exhibited similar variation in intestinal digestion process. The betacyanin retention rate of FHPB kept going down with the increase of digestion time and finally reached $39.20 \%$, indicating the instability of FHPB in intestinal digestion conditions. However, it is noted that after a significant decrease in the first $30 \mathrm{~min}$ of intestinal digestion, the betacyanin retention rate of HPBL maintained well at around $58 \%$ in the rest time. At the end of gastrointestinal digestion, the betacyanin retention rate of HPBL was increased by $40 \%$ as compared to that of the FHPB.
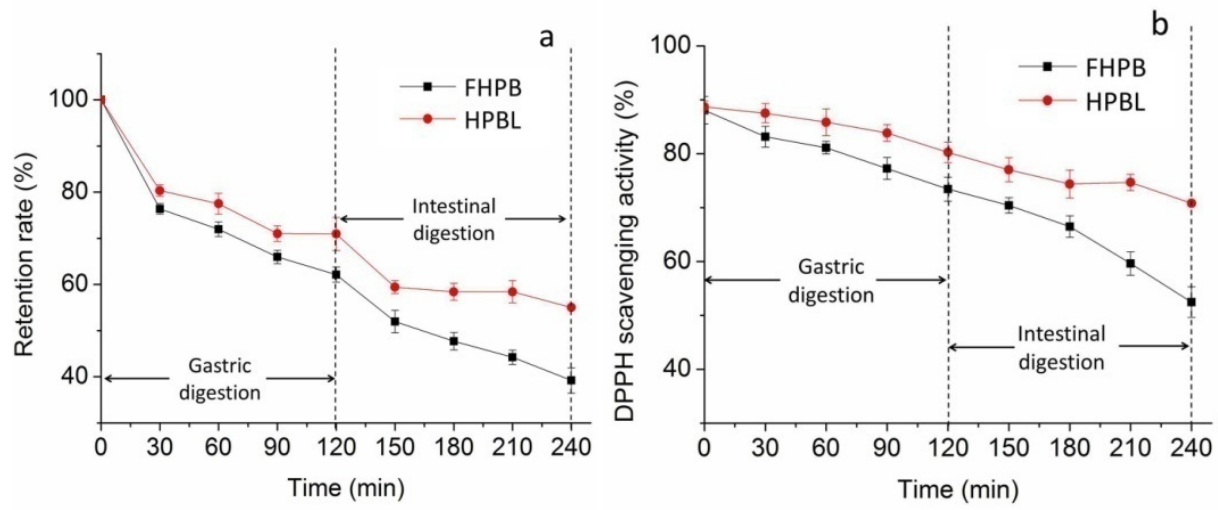

Figure 5. Stability of HPBL during in vitro gastrointestinal digestion: (a) Retention rate of HPBL during in vitro GI digestion; (b) variation of DPPH scavenging activity of HPBL during in vitro GI digestion. 
Figure $5 b$ displays the variations of DPPH scavenging activity of HPBL in stimulated gastrointestinal process. As it is shown, the DPPH scavenging activity of FHPB and HPBL underwent a similar changing pattern with the betacyanin retention rate, suggesting that the antioxidant activity of HPBL was highly correlated with the betacyanin concentration. By protection of the liposome, the DPPH scavenging activity of HPBL was improved by $9 \%$ and $35 \%$ at the end of gastric and intestinal digestion process, respectively.

Previous studies have demonstrated the poor bioavailability of betacyanins by oral administration [16]. In this study, FHPB declined significantly in both the gastric and intestinal digestion process, due to the high acidic environment in the gastric digestion process and the effects of digestive enzymes and bile salts in the intestinal environment. Similar to our results, a previous study found about $75 \%$ and $35 \%$ betanin was metabolized in the stomach and small intestine in vitro, respectively, suggesting that the degradation of betanin in the gastrointestinal tract contributed greatly to its low bioavailability [5]. Tesoriere et al. found a loss of about $50 \%$ in betanin in in vitro oral, gastric, and small intestinal digestion [33]. However, in contrast to our results, Tesoriere et al. also found that betanin remained stable in the gastric digestion process [33]. Montiel-Sánchez et al. found a relative higher stability of betacyanins in cactus berry fruit in the gastric environment than in the intestinal environment [34]. The differences could be explained by the different compositions of betacyanins and the effects of the food matrix [16].

By protection of liposomes, the bioaccessibility of betacyanin was significantly sustained. Consistent with our results, liposomes have been demonstrated to be capable of protecting the targeting ingredients in the gastrointestinal system. Altin et al. encapsulated cocoa hull waste phenolic extract by chitosan-coated liposomes, and found the invitro bioaccessibility was two-fold higher in terms of total phenolic content, total flavonoid content, and total antioxidant capacity [35]. Seguin et al. also found that liposomal fisetin allowed a 47-fold increase in relative bioavailability compared to free fisetin and markedly improved its anticancer efficacy in mice [36].

There is no doubt that the retention of the encapsulated compound in liposomes are closely related with its release behavior, which determines its site of action in the gastrointestinal tract and bioaccessibility. The release behavior of liposomes in the digestion system mainly depends on the environmental parameters, characteristics of the encapsulated compound, and the properties of liposomes. In the aspect of environmental factors, digestive enzymes, $\mathrm{pH}$, the composition and concentration of entrapped compounds, digestion time, and the composition of food matrices are all accounted [32].

Previous studies verified that the structure of liposome remained almost intact, as the gastric lipase had no activity on phospholipids [37]. However, low $\mathrm{pH}$ in the gastric environment could lead to the aggregation of liposomes induced by the reduction in electrostatic repulsive force among liposomes [32]. In this study, about $30 \%$ of loss was observed in betacyanins retention in HPBL in the gastric digestion process. Similarly, evidence showed that the release of lutein and $\beta$-carotene was found to be slow, but the release of lycopene and canthaxanthin was fast in the gastrointestinal system [20]. The reason for the degradation of the entrapped compound without disruption of the liposome may be related to the characteristics of the entrapped compound in the liposome. As mentioned above, entrapped betacyanins could be released from the liposome by penetrating and crossing the liposomal membrane. In addition, some of the betacyanins were just adhered on the surfaces of liposomes. Such betacyanins were exposed to the gastric juice and degraded in the acidic environment.

For the intestinal environment, Liu et al. reported the structure of liposome was greatly damaged in the intestinal digestion process [32]. The pancreatic enzymes including pancreatic lipase, phospholipase A2, and cholesterol esterase, led to the break of the lipid bilayer structure of liposome, and the bile salts further destroyed the phospholipid bilayer [32]. In addition, by induction of bile salts, liposomes could be reconstructed to micelle, which had such an extremely fine particle size that it could permeate and absorb between cells through membrane internalization and lymphatic transportation [32]. 
Due to the above reasons, the destruction of the liposomes in the intestinal environment could promote the release of betacyanins, making the betacyanins available for further intestinal absorption. Meanwhile, the destruction of the liposomes also led the degradation of some released betacyanins. Our results demonstrated that the betacyanin retention rate remained stable from 30 to 120 min of intestinal digestion. It could be deduced that the betacyanins might be protected in phospholipid micelles, which were the digestive products of liposomes by bile salts with fine particle size [6].

Another important factor affecting the release behavior of liposomal ingredients is the properties of liposomes. Liposomal size, thickness, and number of layers of the membrane, as well as modification of liposomal membranes could all affect the release behavior of the encapsulated ingredients [6]. As this was an initial attempt to prepare HPBL, further studies would be conducted to improve the properties of liposomes so as to better control the release of HPBL in gastric digestion process and enable more betacyanins to reach the intestine in active forms.

\section{Materials and Methods}

\subsection{Chemicals and Reagents}

Red pitaya fruits were purchased from a local market in Guangzhou. Soy lecithin and cholesterol were of analytical grade and purchased from Yuanye Biotech Co., Ltd. (Shanghai, China). Sephadex G50 was obtained from Yika Biotech Co., Ltd. (Shanghai, China). DPPH was obtained from Sigma Chemical Company (St. Louis, MO, USA). Pepsin $(10,000 \mathrm{u} / \mathrm{mg})$, pancreatin (250 USPu/mg), and bile salts from pig were purchased from Yuanye Biotech Co., Ltd. (Shanghai, China). All other reagents used were analytical grade.

\subsection{Preparation of $H P B L$}

\subsubsection{Extraction of Betacyanins}

The extraction of betacyanins was conducted according to Song's methods with some modifications [38]. Four hundred grams of HP pulps were homogenized with $800 \mathrm{~mL}$ of cold acidic ethanol solution (80\% ethanol and $0.1 \%$ acetic acid). After storing at $4{ }^{\circ} \mathrm{C}$ for $24 \mathrm{~h}$, the mixture was centrifugated $\left(4^{\circ} \mathrm{C}, 5000 \mathrm{rpm}, 10 \mathrm{~min}\right)$ and the supernatant was collected. Subsequently, the supernatant was concentrated in vacuum at $38{ }^{\circ} \mathrm{C}$ to remove the ethanol, and the betacyanins extracts were obtained.

\subsubsection{Quantification of Betacyanin Content}

Determination of betacyanin contents was performed by the spectrophotometric method, according to Wu's method with some modifications [39]. The betacyanin content was assessed as betanin equivalents by the following equation:

$$
\text { Concentration of betacyanins }(\mathrm{mg} / \mathrm{L})=\frac{\mathrm{A}_{538} \times \mathrm{MW} \times \mathrm{DF} \times 1000}{\varepsilon \times \mathrm{L}}
$$

where $\mathrm{A}_{538}$ is the absorbance value at $538 \mathrm{~nm}$; $\mathrm{MW}$ is the molecular weight of betanin (550 $\mathrm{g} / \mathrm{mol})$; DF is the dilution factor; $\varepsilon$ is the molar extinction coefficient of betanin $(61,600 \mathrm{~L} /(\mathrm{mol} \cdot \mathrm{cm}))$; and $\mathrm{L}$ is the path length of the cuvette. All determinations were performed in triplicate.

\subsubsection{Preparation of Liposomes}

The liposome was prepared by the thin-layer dispersion method according to Amjadi's methods with some modifications [13]. Certain amounts of lecithin and cholesterol were dissolved in ethanol. The ethanol was then removed by rotary evaporator at $50{ }^{\circ} \mathrm{C}$ under vacuum (EYELA N-1000, Tokyo Rikakikai Co., Ltd., Tokyo, Japan), and a thin layer was formed on the wall of the round bottom flask. The thin layer was then dissolved by adding $50 \mathrm{~mL}$ of distilled water and transferred to a $100 \mathrm{~mL}$ volumetric flask. Subsequently, the solution was diluted to $100 \mathrm{~mL}$ by adding certain amounts of HP betacyanin extracts. Then, the liposomal suspension was homogenized for 10 min twice in an ice bath. Finally, the 
liposomal dispersions were sonicated at an intensity of $600 \mathrm{~W}$ using an ultrasonic cleaner for 1 min eight times in an ice bath, and the HPBL solution was prepared.

\subsubsection{Separation of HPBL and FHPB}

The HPBL solution was extracted with ethyl acetate. Then, the aqueous layer was collected and applied to gel filtration chromatography of $1 \times 20 \mathrm{~cm}$ column packed with pre-swollen Sephadex ${ }^{\circledR}$ G50. Subsequently, samples were eluted by deionized water at a flow rate of $1 \mathrm{~mL} / \mathrm{min}$. The fractions were collected and detected by the spectrophotometer at $538 \mathrm{~nm}$.

\subsubsection{Determination of EE}

Concentration of FHPB was determined, and the encapsulation efficiency (EE) was calculated according to the following equation. All determinations were performed in triplicate.

$$
\mathrm{EE}(\%)=\frac{\text { Total betacyanin content }- \text { FHPB content }}{\text { Total betacyanin content }} \times 100
$$

\subsection{Optimization of the Formulation Parameters for Preparation of HPBL}

Central composite design was employed to optimize formulation parameters for encapsulation as shown in Table 1. The software Design Expert was employed for experimental design, data analysis, and model building. Three variables used in this study were $\mathrm{HP}$ extract concentration $\left(\mathrm{X}_{1}\right)$, lecithin-to-cholesterol ratio $\left(\mathrm{X}_{2}\right)$, and lecithin concentration $\left(X_{3}\right)$, respectively, with three levels for each variable, while the dependent variable was the EE of HP betacyanins. The triplicates were performed at all design points in randomized order. Experimental data were fitted to a quadratic polynomial model and regression coefficients were obtained. The non-linear computer-generated quadratic model used in the response surface was as follows:

$$
Y_{0}=\beta_{0}+\sum_{j=1}^{k} \beta_{j} X_{j}+\sum_{j=1}^{k} \beta_{j j} X_{j}^{2}+\sum \sum_{i \prec j} \beta_{j i} X_{i} X_{j}
$$

where $Y_{0}$ is the measured response associated with each factor lever combination; and $\beta_{0}$, $\beta_{\mathrm{j}}, \beta_{\mathrm{jj}}$, and $\beta_{\mathrm{ji}}$ are the regression coefficients for intercept, linearity, square, and interaction; while $X_{i}$ and $X_{j}$ are the independent coded variables, respectively.

\subsection{Analysis of Properties of HPBL}

3.4.1. Determination of $\zeta$-Potential, Particle Size, and Polydispersity Index

$\zeta$-Potential, particle size, and polydispersity index (PDI) of HPBL were determined with a Nano particle analyzer (SZ-100Z, HORIBA, Ltd., Tokyo, Japan). All measurements were performed at $25^{\circ} \mathrm{C}$. Each measurement of particle size and PDI was performed with a scattering angle of $90^{\circ}$. All determinations were performed in triplicate.

\subsubsection{Morphology Observation}

Morphology of HPBL was observed by TEM. A drop of liposome dispersion was placed on a 200 mesh copper grid with formvar/carbon film, adhered for $3 \mathrm{~min}$, and blotted dry. Then, samples were stained with phosphotungstic acid at $1 \%(w / v)$ for 3 min. After natural drying, specimens were observed using a TEM (HT7700, Hitachi Co., Ltd., Tokyo, Japan) at an accelerating voltage of $80.0 \mathrm{kV}$.

\subsubsection{Determination of DPPH Radical Scavenging Activity}

DPPH radical scavenging activity of betacyanins was evaluated according to BrandWilliams's method with some modifications [40]. Two milliliters of the diluted samples were mixed with $2 \mathrm{~mL}$ DPPH solution $(0.14 \mathrm{mmol} / \mathrm{L})$ properly and kept in the dark at 
ambient temperature for $30 \mathrm{~min}$. Then, the absorbance of the mixture was measured at $517 \mathrm{~nm}$. The control was performed using distilled water to take the place of the sample. The blank was carried out using ethanol. The DPPH radical scavenging activity was determined through the following formula:

$$
\mathrm{DPPH} \text { radical scavenging activity }=\frac{\mathrm{A}_{\text {control }}-\mathrm{A}_{\text {sample }}}{\mathrm{A}_{\text {control }}} \times 100 \%
$$

where $\mathrm{A}_{\text {control }}$ is the absorbance value of the control; $\mathrm{A}_{\text {sample }}$ is the absorbance value of the sample. All determinations were performed in triplicate.

\subsubsection{Evaluation of Color Value}

The color of the sample was measured using a colorimeter (Ultrascan VIS, Hunter Associates Laboratory, Reston, VA, USA) fitted with a $25 \mathrm{~mm}$ diameter aperture. The colorimeter was calibrated using the black and white tiles provided. Evaluation of the color of HPBL suspension was expressed by $L^{*}, a^{*}$, and $b^{*}$ values, which represented the whiteness, the redness when positive, and the yellowness when positive, respectively.

\subsection{Storage Stability Evaluation of HPBL}

\subsubsection{Temperature Stability Evaluation}

To determine the temperature stability of HPBL, HPBL dispersions were stored at $4{ }^{\circ} \mathrm{C}$ (refrigerated condition), $25^{\circ} \mathrm{C}$ (ambient condition), and $37^{\circ} \mathrm{C}$ (accelerated condition) for 21 days. Samples were collected at an interval of 7 days, and color values were determined. Before analyzing the betacyanin retention rate and DPPH radical scavenging activity, samples were diluted with methanol $(1: 10 \mathrm{v} / \mathrm{v})$ and sonicated at an intensity of $600 \mathrm{~W}$ for 10 min to break the liposomes. All determinations were performed in triplicate.

\subsubsection{PH Stability Evaluation}

To determine the $\mathrm{pH}$ stability of HPBL, $\mathrm{pH}$ value of HPBL dispersion was adjusted to $\mathrm{pH} 3,5$, and 7 , respectively. Coupled with the original $\mathrm{pH} 4.3$ of the HPBL dispersion, the stabilities of HPBL in the four different $\mathrm{pH}$ conditions were evaluated at $25^{\circ} \mathrm{C}$ for a storage of 21 days. Samples were collected at an interval of 7 days, and color values were determined. Before analyzing the betacyanin retention rate, and DPPH radical scavenging activity, samples were diluted with methanol $(1: 10 v / v)$ and sonicated at an intensity of $600 \mathrm{~W}$ for $10 \mathrm{~min}$ to break the liposomes. All determinations were performed in triplicate.

\subsection{In Vitro Gastrointestinal Stability Evaluation of HPBL}

An in vitro simulated gastrointestinal tract (GIT) model was applied according to Tai's method with some modifications [41]. The GIT model included gastric phase and small intestine phase. For the stimulated gastric juice (SGJ), $800 \mathrm{~mL}$ of distilled water were mixed with $16.4 \mathrm{~mL}$ of $5 \mathrm{M} \mathrm{HCl}$. Then the $\mathrm{pH}$ was adjusted to 1.2 by dropwise addition of $1 \mathrm{M}$ $\mathrm{HCl}$. After sterilization, the mixture was added with $10 \mathrm{~g}$ of pepsin. For the stimulated small intestinal juice (SIJ), $6.8 \mathrm{~g}$ of $\mathrm{K}_{2} \mathrm{HPO}_{4}$ were dissolved in $500 \mathrm{~mL}$ of distilled water, and the $\mathrm{pH}$ was adjusted to 6.8 by dropwise addition of $0.1 \mathrm{M} \mathrm{NaOH}$. After sterilization, the mixture was added with $2 \mathrm{~g}$ of bile salts and $10 \mathrm{~g}$ of pancreatin.

All simulated digestive juices and liposomes were preheated at $37^{\circ} \mathrm{C}$, and the whole stimulating digestive process was conducted at a speed of $95 \mathrm{rpm}$ in $37^{\circ} \mathrm{C}$ water bath. Firstly, for stimulating gastric digestion, HPBL solution and SGF were mixed 1:1 by volume and stirring for $2 \mathrm{~h}$. Samples were collected at an interval of $30 \mathrm{~min}$. Then, the $\mathrm{pH}$ of the gastric digestive solution was adjusted to 6.8 and mixed with SIF by a volume ratio of 1:1. During the $2 \mathrm{~h}$ of stimulated small intestinal digestion, samples were also collected at an interval of $30 \mathrm{~min}$. For calculation of the betacyanin retention rate and DPPH scavenging capacity, digestive samples were diluted with methanol $(1: 10 v / v)$ and sonicated at an 
intensity of $600 \mathrm{~W}$ for $10 \mathrm{~min}$ to break the liposomes. The betacyanin retention rate was calculated according to the following equation:

$$
\text { Retention rate }=\frac{\text { Final total betacyanin content }}{\text { Initial total betacyanin content }} \times 100 \%
$$

\subsection{Statistical Analysis}

Each experiment was performed in triplicate, and three samples from each treatment at each sampling day were analyzed. Results were expressed as mean \pm standard deviation (SD). Comparisons of means were determined by ANOVA (analysis of variance) using SPSS 19 (SPSS Inc., Chicago, IL, USA) with significance set at $p<0.05$.

\section{Conclusions}

In this study, liposomes technology was applied for encapsulation of HP betacyanins. The formulation parameters of HP extract concentration, lecithin-to-cholesterol ratio, and lecithin concentration were optimized to achieve an HP betacyanin EE of $93.43 \pm 0.11 \%$. The HPBL was characterized to be in nanometer range, physically stable, and have no impact on the antioxidant capacity of HP betacyanins. By liposomal encapsulation, HP betacyanin retention was demonstrated to be greatly enhanced in different storage temperatures $\left(4^{\circ} \mathrm{C}\right.$, $25^{\circ} \mathrm{C}$ and $37^{\circ} \mathrm{C}$ and different $\mathrm{pH}$ conditions ( $\mathrm{pH} 3.0-7.0$ ) for up to 21 days. The color deterioration and loss in antioxidant capacity of HP betacyanins were effectively alleviated as well. In vitro gastrointestinal digestion revealed that the retention rate of HP betacyanin was significantly improved. This was a preliminary study for the application of liposomal technology in the development of a natural colorant based on HP betacyanins with the purpose of improving the storage stability and bioaccessibility of HP betacyanins. The results indicated the feasibility of the attempt. However, liposomal formulation still needs to be optimized to further enhance the stability of the HPBL and better avoid the leakage of encapsulated betacyanins. Moreover, the composition of the HP extracts and their interaction with liposomes also need investigation to better understand the complex system.

Author Contributions: Conceptualization, X.L., B.X. and Y.X.; methodology, X.L. and B.L.; validation, J.W. (Jing Wen); formal analysis, X.L., J.W. (Jing Wen) and D.T.; investigation, B.L. and J.W. (Jijun Wu); resources, Y.X. and B.X.; data curation, X.L. and J.W. (Jijun Wu); writing-original draft preparation, X.L.(Xian Lin); writing-review and editing, D.T., Y.Y. and B.X.; supervision, B.X.; project administration, Y.Y.; funding acquisition, Y.X. All authors have read and agreed to the published version of the manuscript.

Funding: This work was supported by Guangdong Academy of Agricultural Sciences, grant number 202109TD; Agriculture and Rural Affairs Department of Guangdong Province, grant number 2020KJ116; Science and Technology Department of Maoming, grant number KJ057 and R202107 from BNU-HKBU United International College.

Institutional Review Board Statement: Not applicable.

Informed Consent Statement: Not applicable.

Data Availability Statement: Not applicable.

Acknowledgments: Special thanks to Charles Brennan for providing important suggestions.

Conflicts of Interest: The authors declare no conflict of interest.

Sample Availability: Samples of the compounds are not available from the authors.

\section{References}

1. Wiset, L.; Srilaong, V. Comparisons of antioxidant activity and bioactive compounds of dragon fruit peel from various drying methods. World Acad. Sci. Eng. Technol. 2012, 6, 994-997.

2. Strack, D.; Vogt, T.; Schliemann, W. Recent advances in betalain research. Phytochemistry 2003, 62, 247-269. [CrossRef]

3. Madadi, E.; Mazloum-Ravasan, S.; Yu, J.S.; Ha, J.W.; Hamishehkar, H.; Kim, K.H. Therapeutic application of betalains: A review. Plants 2020, 9, 1219. [CrossRef] [PubMed] 
4. Khan, M.I. Stabilization of betalains: A review. Food Chem. 2016, 197, 1280-1285. [CrossRef] [PubMed]

5. Krantz, C.; Monier, M.; Wahlström, B. Absorption, excretion, metabolism and cardiovascular effects of beetroot extract in the rat. Food Cosmet. Toxicol. 1980, 18, 363-366. [CrossRef]

6. Shishir, M.R.I.; Karim, N.; Gowd, V.; Zheng, X.; Chen, W. Liposomal delivery of natural product: A promising approach in health research. Trends Food Sci. Technol. 2019, 85, 177-200. [CrossRef]

7. Guldiken, B.; Gibis, M.; Boyacioglu, D.; Capanoglu, E.; Weiss, J. Physical and chemical stability of anthocyanin-rich black carrot extract-loaded liposomes during storage. Food Res. Int. 2018, 108, 491-497. [CrossRef]

8. Zhao, L.; Temelli, F.; Chen, L. Encapsulation of anthocyanin in liposomes using supercritical carbon dioxide: Effects of anthocyanin and sterol concentrations. J. Funct. Foods 2017, 34, 159-167. [CrossRef]

9. Nogueira, E.; Gomes, A.C.; Pret, A.; Cavaco-Paulo, A. Design of liposomal formulations for cell targeting. Colloids Surfaces B Biointerfaces 2015, 136, 514-526. [CrossRef] [PubMed]

10. Andar, A.U.; Hood, R.R.; Vreeland, W.N.; Devoe, D.L.; Swaan, P.W. Microfluidic preparation of liposomes to determine particle size influence on cellular uptake mechanisms. Pharm. Res. 2014, 31, 401-413. [CrossRef] [PubMed]

11. Nagayasu, A.; Uchiyama, K.; Kiwada, H. The size of liposomes: A factor which affects their targeting efficiency to tumors and therapeutic activity of liposomal antitumor drugs. Adv. Drug Deliv. Rev. 1999, 40, 75-87. [CrossRef]

12. Marín, D.; Alemán, A.; Sánchez-Faure, A.; Montero, P.; Gómez-Guillén, M.C. Freeze-dried phosphatidylcholine liposomes encapsulating various antioxidant extracts from natural waste as functional ingredients in surimi gels. Food Chem. 2018, 245, 525-535. [CrossRef]

13. Amjadi, S.; Ghorbani, M.; Hamishehkar, H.; Roufegarinejad, L. Improvement in the stability of betanin by liposomal nanocarriers: Its application in gummy candy as a food model. Food Chem. 2018, 256, 156-162. [CrossRef] [PubMed]

14. Da Silva Malheiros, P.; Sant'Anna, V.; Micheletto, Y.M.S.; Da Silveira, N.P.; Brandelli, A. Nanovesicle encapsulation of antimicrobial peptide P34: Physicochemical characterization and mode of action on Listeria monocytogenes. J. Nanoparticle Res. 2011, 13, 3545-3552. [CrossRef]

15. Zhao, L.; Temelli, F. Preparation of anthocyanin-loaded liposomes using an improved supercritical carbon dioxide method. Innov. Food Sci. Emerg. Technol. 2017, 39, 119-128. [CrossRef]

16. Khan, M.I. Plant betalains: Safety, antioxidant activity, clinical efficacy, and bioavailability. Compr. Rev. Food Sci. Food Saf. 2016, 15, 316-330. [CrossRef]

17. He, J. Calculation of Excited States and One-Electron Reduction Potentials of Betalain Natural Plant Pigments. Master Thesis, Tianjin University, Tianjin, China, May 2019.

18. Taira, J.; Tsuchida, E.; Katoh, M.C.; Uehara, M.; Ogi, T. Antioxidant capacity of betacyanins as radical scavengers for peroxyl radical and nitric oxide. Food Chem. 2015, 166, 531-536. [CrossRef]

19. Liu, Y.; Liu, D.; Zhu, L.; Gan, Q.; Le, X. Temperature-dependent structure stability and in vitro release of chitosan-coated curcumin liposome. Food Res. Int. 2015, 74, 97-105. [CrossRef]

20. Liu, W.; Ye, A.; Han, F.; Han, J. Advances and challenges in liposome digestion: Surface interaction, biological fate, and GIT modeling. Adv. Colloid Interface Sci. 2019, 263, 52-67. [CrossRef] [PubMed]

21. Maherani, B.; Arab-Tehrany, E.; Kheirolomoom, A.; Geny, D.; Linder, M. Calcein release behavior from liposomal bilayer; Influence of physicochemical/mechanical/structural properties of lipids. Biochimie 2013, 95, 2018-2033. [CrossRef]

22. Herbach, K.M.; Stintzing, F.C.; Carle, R. Betalain stability and degradation-Structural and chromatic aspects. J. Food Sci. 2006, 71, 41-50. [CrossRef]

23. Gandía-Herrero, F.; Cabanes, J.; Escribano, J.; García-Carmona, F.; Jiménez-Atiénzar, M. Encapsulation of the most potent antioxidant betalains in edible matrixes as powders of different colors. J. Agric. Food Chem. 2013, 61, 4294-4302. [CrossRef] [PubMed]

24. Stintzing, F.C.; Carle, R. Functional properties of anthocyanins and betalains in plants, food, and in human nutrition. Trends Food Sci. Technol. 2004, 15, 19-38. [CrossRef]

25. Roy, K.; Gullapalli, S.; Chaudhuri, U.R.; Chakraborty, R. The use of a natural colorant based on betalain in the manufacture of sweet products in India. Int. J. Food Sci. Technol. 2004, 39, 1087-1091. [CrossRef]

26. Gandía-Herrero, F.; Jiménez-Atiénzar, M.; Cabanes, J.; García-Carmona, F.; Escribano, J. Stabilization of the bioactive pigment of opuntia fruits through maltodextrin encapsulation. J. Agric. Food Chem. 2010, 58, 10646-10652. [CrossRef]

27. Montes-Lora, S.; Hurtado, N.; Mosquera, N.; Heredia, F.J.; Cejudo-Bastante, M.J. Effect of technological practices on individual betalains and antioxidant activity of Columbian betalain-rich raw materials. Int. J. Food Sci. Technol. 2016, 51, 1041-1047. [CrossRef]

28. Celli, G.B.; Brooks, M.S.L. Impact of extraction and processing conditions on betalains and comparison of properties with anthocyanins-A current review. Food Res. Int. 2017, 100, 501-509. [CrossRef]

29. Gliszczynska-Swiglo, A.; Szymusiak, H.; Malinowska, P. Betanin, the main pigment of red beet: Molecular origin of its exceptionally high free radical-scavenging activity. Food Addit. Contam. 2005, 11, 1079-1087. [CrossRef]

30. Gandía-Herrero, F.; Escribano, J.; García-Carmona, F. Purification and antiradical properties of the structural unit of betalains. J. Nat. Prod. 2012, 75, 1030-1036. [CrossRef]

31. Rodríguez-Sánchez, J.A.; Cruzy Victoria, M.T.; Barragán-Huerta, B.E. Betaxanthins and antioxidant capacity in Stenocereus pruinosus: Stability and use in food. Food Res. Int. 2017, 91, 63-71. [CrossRef] 
32. Liu, W.; Hou, Y.; Jin, Y.; Wang, Y.; Xu, X.; Han, J. Research progress on liposomes: Application in food, digestion behavior and absorption mechanism. Trends Food Sci. Technol. 2020, 104, 177-189. [CrossRef]

33. Tesoriere, L.; Fazzari, M.; Angileri, F.; Gentile, C.; Livrea, M.A. In vitro digestion of betalainic foods. Stability and bioaccessibility of betaxanthins and betacyanins and antioxidative potential of food digesta. J. Agric. Food Chem. 2008, 56, 10487-10492. [CrossRef]

34. Montiel-Sánchez, M.; García-Cayuela, T.; Gómez-Maqueo, A.; García, H.S.; Cano, M.P. In vitro gastrointestinal stability, bioaccessibility and potential biological activities of betalains and phenolic compounds in cactus berry fruits (Myrtillocactus geometrizans). Food Chem. 2021, 342, 128087. [CrossRef] [PubMed]

35. Altin, G.; Gültekin-Özgüven, M.; Ozcelik, B. Liposomal dispersion and powder systems for delivery of cocoa hull waste phenolics via Ayran (drinking yoghurt): Comparative studies on in-vitro bioaccessibility and antioxidant capacity. Food Hydrocoll. 2018, 81, 364-370. [CrossRef]

36. Seguin, J.; Brullé, L.; Boyer, R.; Lu, Y.M.; Ramos Romano, M.; Touil, Y.S.; Scherman, D.; Bessodes, M.; Mignet, N.; Chabot, G.G. Liposomal encapsulation of the natural flavonoid fisetin improves bioavailability and antitumor efficacy. Int. J. Pharm. 2013, 444, 146-154. [CrossRef]

37. Liu, W.; Ye, A.; Liu, W.; Liu, C.; Han, J.; Singh, H. Behaviour of liposomes loaded with bovine serum albumin during in vitro digestion. Food Chem. 2015, 175, 16-24. [CrossRef] [PubMed]

38. Song, H.; Chu, Q.; Xu, D.; Xu, Y.; Zheng, X. Purified betacyanins from Hylocereus undatus peel ameliorate obesity and insulin resistance in high-fat-diet-fed mice. J. Agric. Food Chem. 2016, 64, 236-244. [CrossRef] [PubMed]

39. Wu, L.C.; Hsu, H.W.; Chen, Y.C.; Chiu, C.C.; Lin, Y.I.; Ho, J.A.A. Antioxidant and antiproliferative activities of red pitaya. Food Chem. 2006, 95, 319-327. [CrossRef]

40. Brand-Williams, W.; Cuvelier, M.E.; Berset, C. Use of a free radical method to evaluate antioxidant activity. LWT Food Sci. Technol. 1995, 28, 25-30. [CrossRef]

41. Tai, K.; Rappolt, M.; Mao, L.; Gao, Y.; Yuan, F. Stability and release performance of curcumin-loaded liposomes with varying content of hydrogenated phospholipids. Food Chem. 2020, 326, 126973. [CrossRef] 